\title{
Alignment errors in Poggendorff-like displays when the variable segment is a dot, a dot series, or a line
}

\author{
PETER WENDEROTH \\ University of Sydney, Sydney, New South Wales 2006, Australia
}

\begin{abstract}
In the standard Poggendorff figure, the abutting tip of the upper right transversal appears more misaligned than its distal tip. This appears paradoxical, since dot alignment errors increase with line-to-dot separation. To attempt a resolution of the paradox, four experiments were conducted in which single dots, series of dots, and lines were adjusted to be apparently collinear with a standard line segment, with neither, one, or both vertical inducing lines present. The results, taken together, suggested an explanation of the paradox and also that the standard Poggendorff display may result in alignment errors which represent a compromise judgment, based on conflicting cues to collinearity. In particular, the fourth experiment showed that line-to-line alignment errors could be made to resemble dot-to-line alignment errors by instructional variables. It was suggested that the effect was produced by forcing observers to process asymmetrically rather than symmetrically (Krantz \& Weintraub, 1973).
\end{abstract}

The Poggendorff illusion is shown in Figure 1, and the usual observation is that the whole line segment $C D$ appears to lie above the virtual extension of segment $\mathrm{AB}$, although the two segments in fact are collinear. However, another observation can be made on this display: Of the two line endpoints, $\mathrm{C}$ and $\mathrm{D}$, which appears less collinear with $\mathrm{AB}$ ? Most observers agree, and some preliminary experiments have shown (Wenderoth, 1980, in press), that point $C$ appears vertically displaced above the extension of $\mathrm{AB}$ more than does point $\mathrm{D}$.

This observation raises numerous problems for a variety of current theories of the illusion. For example, one theory asserts that a component of the illusion is due to acute-angle expansion (see Wenderoth, Beh, \& White, 1978). Figure 2A demonstrates that any perceived misalignment which derived from this effect should be the same for points $C$ and $D$ (assuming that the two transverse segments undergo equal angular displacements). This is true even if the pivot of the angular change is within the line (Figure 2B) or even at its far tip (Figure 2C).

Another suggestion (Wenderoth, Beh, \& White, 1978 ) is that segments $A B$ and $C D$ imply are displaced perceptually down and up, respectively, as in Figure 2D. Again, such an effect would predict equivalent perceptual misalignments of points $C$ and $\mathrm{D}$; and a combination of angular and linear displacements also predicts no difference, since this merely

This research was supported, in part, by The Australian Research Grants Committee (Grant A74/15177) and the University of Sydney in 1979. I am grateful to Terry Smith, who developed the computer programs and assisted in testing the subjects. changes the pivot point of the transversals (Figure $2 \mathrm{E}$ ). A currently popular view that the transverse line segments bow or bend slightly at the point of intersect (e.g., Chiang, 1968; Restle, 1969; Walker, 1973; Wenderoth, Beh, \& White, 1978; Wenderoth, Parkinson, \& White, 1979) actually predicts the opposite result, that $\mathrm{D}$ should appear more misaligned than $\mathrm{C}$ (Figure $2 \mathrm{~F}$ ).

This latter discrepancy between predicted and observed differences could be due, at least in the experiments of Wenderoth et al., to differences between their stimuli and the standard Poggendorff display (Figure 1). First, Wenderoth, Beh, and White

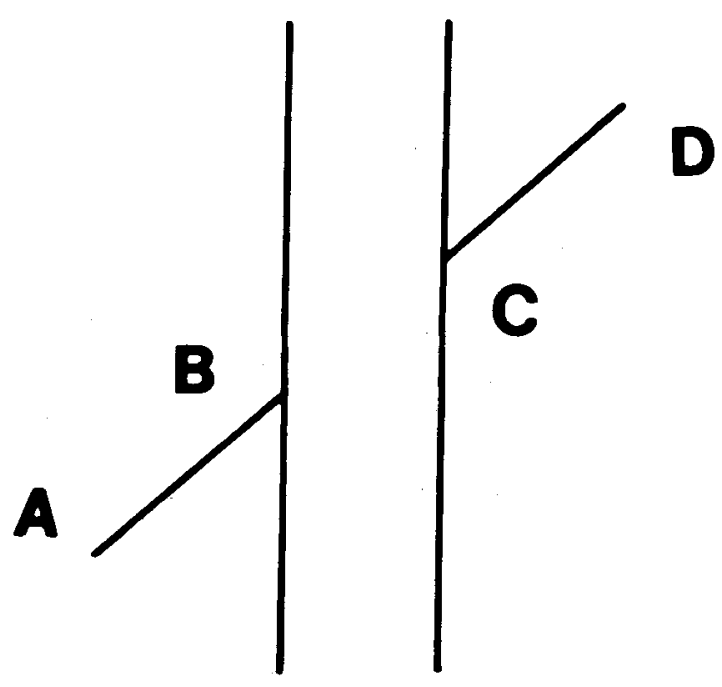

Figure 1. The Poggendorff illusion. 
A
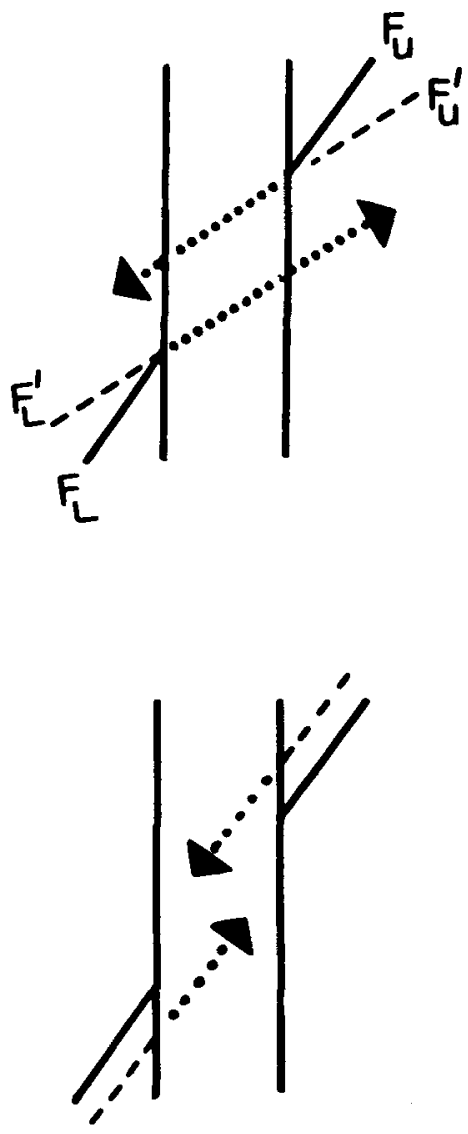

D
$\mathbf{B}$
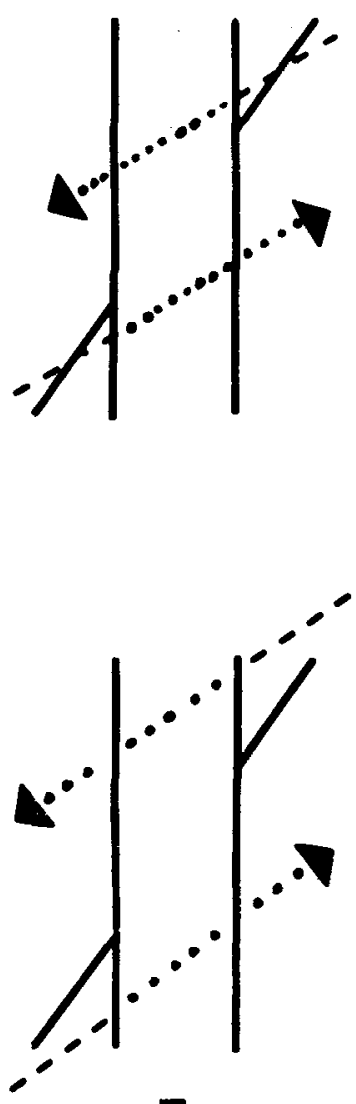

$\mathbf{E}$
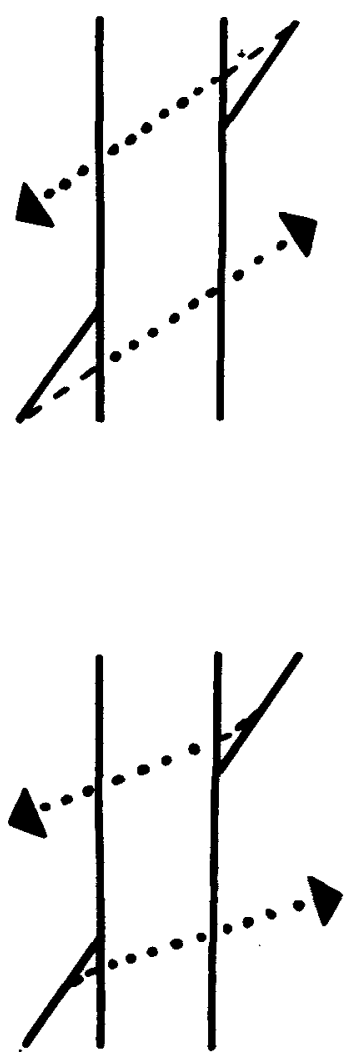

$\boldsymbol{F}$

Figure 2. Various possible displacements of Poggendorff transversals (dashed lines) and consequent perceived extensions (dotted arrows). For details, see text.

used a version of the illusion in which only one of the two vertical (inducing) lines was present, the left line in Figure 1. Second, they replaced the right-hand transversal segment (CD in Figure 1) with a dot which could vary in distance from point B. In order to study the effects of such stimulus properties, four experiments are reported here. The aim was to discover whether the initial observation that point $D$ in Figure 1 appears less displaced than point $C$ is inconsistent with the hypothesized perceptual bowing or bending of the transversal segments at the point of intersect, or whether figural differences alone could somehow account for the apparent discrepancy.

\section{EXPERIMENT 1}

The purpose of Experiment 1 was to provide some initial data relating to (a) the role of the second parallel in the Poggendorff display, and (b) the possible difference between variable dots and variable line segments. Although actual lines were used later, in Experiments 3 and 4, Experiment 1 observers attempted to construct straight segments from a series of dots.

There were four treatment conditions in the experiment, each comprising an experimental and a control condition. These four treatments (experimental conditions) are depicted in Figure 3 and can be described, briefly, as follows:

Single (1). The term "single" refers to the fact that only the left-hand vertical inducing line was present in the experimental condition. The numeral 1 indicates that only one dot for alignment was visible on any trial. However, between trials, the dot varied its position between the 10 positions shown in the figure below it, which represents:

Single (10). This condition was similar to Single (1) except that all 10 dots were always visible and were initially randomly scattered around the true transversal extension. The task was to bring the dots, one at 
Single 1

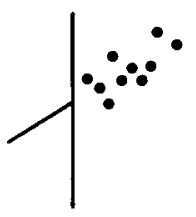

Single 10

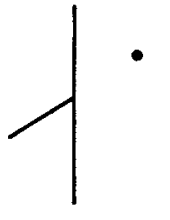

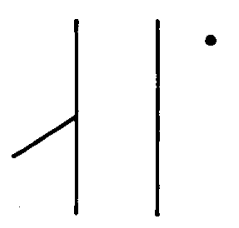

Double 1

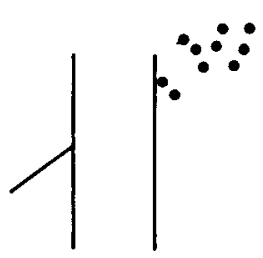

Double 10
Figure 3. Treatment conditions, Experiment 1 (see text).

a time and in random order, to form a straight line extension of the transversal.

Double (1). This condition differed from Single (1) only in that both vertical inducing lines were present. The 10 possible dot positions were all shifted to the right of the right-hand vertical line, as shown below for:

Double (10). This condition was similar to Double (1) in that the 10 dot positions were shifted to the right of the second vertical line. Otherwise, the display and task were identical to Single (10). In both of the Double conditions, the position of the right-hand vertical coincided with the fifth dot from the vertical in the two Single conditions. Hence, the horizontal coordinates (left to right) of dots $6,7,8$, 9, and 10 in the Single conditions coincided with those of dots $1,2,3,4$, and 5 in the Double conditions.

The rationale for including these four treatment conditions was as follows. Condition Single 1 virtually replicates the experimental conditions used by Wenderoth, Beh, and White (1978), and hence was expected to result in a linear increase in alignment errors as a function of line-to-dot separation. The problem, then, is whether the observed decrease in apparent misalignment at the far tip of the transverse segment in Figure 1 is due to one or more of the following: the fact that $\mathrm{CD}$ is a line; the presence of the second parallel; or merely the distance of point $D$ from AB (i.e., there could be a linear increase in dot alignment errors up to a certain distance, followed by a decrease; this is one reason it was useful to employ a large display screen with large stimuli here). Thus, Condition Single 10 provides a line-like variable stimulus but at the closer distance and without a second parallel; Condition Double 1 has a second parallel, increased dot distance in some cases, but only one alignment dot; and Condition Double 10 has the second parallel, some more distant dots, and a line-like variable stimulus as well.

\section{Method \\ Apparatus. A PDP-8/E computer was interfaced with a Hewlett-} Packard 1317 visual display (P4 phosphor) to produce the stimulus figures in the center of the slightly curved screen. ${ }^{\prime}$ The observer sat $48 \mathrm{~cm}$ from the screen, head in a padded chinrest, with the index finger of each hand resting on a microswitch. A press on one switch caused a displayed dot to move up vertically at a velocity of $1.33 \mathrm{~mm}(9.5 \mathrm{~min}$ of arc) $/ \mathrm{sec}$. A second press stopped the dot, and presses after that alternately started and stopped it. The other switch had an identical function, except that it caused the dot to move down. Dot starting positions were determined randomly by the computer, with the restriction that they be within $\pm 20 \mathrm{~mm}$ of true alignment. In the "1" conditions, the sequence of dot appearances was random over Positions 1 to 10 , although the observer had to decide upon a final position for each dot, then depress a third, centrally located microswitch to indicate that decision, before the next dot appeared. In the " 10 " conditions, the 10 dots were always visible, but the position of the movable dot was sequenced randomly. In these conditions, dots remained on the screen whether they had already been subjectively aligned or not, so that the observer could, in principle have finished with 10 truly aligned dots on the screen.

Visual display. The display was calibrated with $\mathrm{X}$ and $\mathrm{Y}$ gains set such that one dot measured $.16 \mathrm{~mm}$. Hence, one dot subtended $1 \mathrm{~min} 9 \mathrm{sec}$ of arc at the eye. ${ }^{2}$ The oblique $\left(45^{\circ}\right.$ to vertical) transverse line segment was $44.8 \mathrm{~mm}$ long ( $5 \mathrm{deg} 21 \mathrm{~min}$ of arc), the vertical inducing lines, when present, were $160 \mathrm{~mm}$ long (19 deg $5 \mathrm{~min}$ ), and the 10 dot positions were separated obliquely by $4.48 \mathrm{~mm}$ ( $32 \mathrm{~min}$ of arc). In the Single conditions, the first dot position was also $4.48 \mathrm{~mm}$ from the termination of the oblique line segment (point of abuttal). In the Double conditions, the first dot was $4.48 \mathrm{~mm}$ oblique from the second parallel and the space between the parallels was $15.84 \mathrm{~mm}$ horizontally (1 deg $53 \mathrm{~min}$ ). The luminance of display lines and dots, in the windowless and totally dark laboratory cubicle, was about $2 \mathrm{~cd} / \mathrm{m}^{2}$, measured by an SEI photometer, and contrast of the stimuli, defined as $\left(\mathrm{L}_{\max }-\mathrm{L}_{\min }\right) /\left(\mathrm{L}_{\max }+\mathrm{L}_{\min }\right)$, approximated $1.0 .^{3}$

Procedure. Test sessions lasted $1 \mathrm{~h}$, and each subject completed 16 conditions, in random order, 8 of which comprise this experiment (the remaining 8 conditions are discussed here as Experiment 2). The 8 conditions were the 4 experimental conditions described previously in relation to Figure 3 and their respective control conditions, which were identical except that no vertical lines were present.

Instructions to the subject stressed accuracy, and in the "10" conditions particular emphasis was made of the following point: Figure 4 shows two examples of hypothetical alignment errors. In one case (A), the dots do not fall on a line but $6 / 10$ are correctly
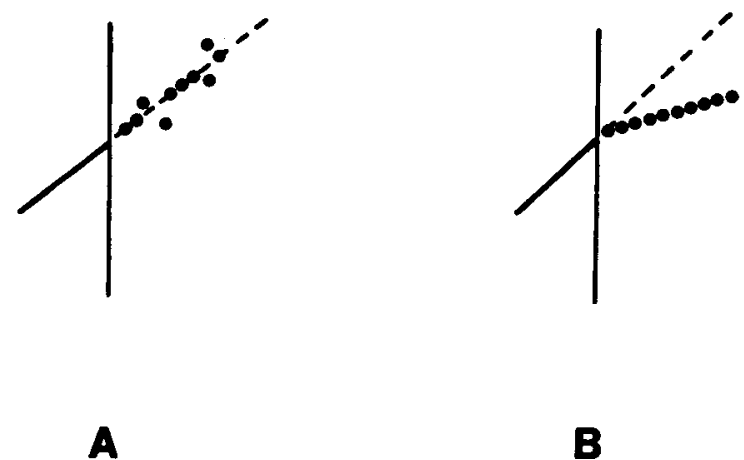

$\mathbf{B}$

Figure 4. Figure similar to that shown to observers in Experiments 1 and 2 in the Single (10) and Double (10) conditions (see text). 
aligned. In B, only 1 dot is truly aligned, but the 10 dots do form a straight line. All subjects were shown this kind of drawing and were told that their task was to get as many dots correctly aligned as possible. Hence, a result like $A$ would be better than a result like'B.

Subjects. Thirteen volunteers from an introductory psychology course, five males and eight females, took part. All had emmetropic or corrected vision, and none reported any extreme difficulty with the task.

\section{Results}

Mean alignment errors and associated standard errors are shown for the control (C) conditions (no verticals) and experimental (E) conditions in Tables 1 and 2 , respectively.

The difference scores $(E-C)$ are shown in Figure 5. In all cases, positive errors are settings which are too low, in the usual Poggendorff illusion direction.

It is obvious in Tables 1 and 2 that standard errors tended to increase with line-to-dot separation, a common finding (Wenderoth, Beh, \& White, 1978), but on the assumption that the analysis of variance is robust to departures from variance homogeneity, and because planned contrasts involved only gross tests of trend rather than comparisons between individual means, the $(\mathrm{E}-\mathrm{C})$ data were analyzed using a simple Subjects by Treatments design (Winer, 1962, p. 112). First, each of the four treatments in Figure 5 was tested for significant linear, quadratic, and residual trend. Second, the three remaining contrasts tested for overall differences between: Double (1) and
Double (10); Single (1) and Single (10); and overall Single vs. Double conditions.

The results were as follows. None of the residual or quadratic trend components was significant [critical $F(1,468)=3.84 ; p>.05$ in every case], although the Double (10) quadratic component approached significance $(F=2.07)$. Only two linear trends were significant, those for Single (1) with $F=14.73(p<.001)$ and Double (1) with $F=4.64(p<.05)$, but, again, the Single (10) linear component was relatively large $(\mathrm{F}=2.79)$.

The remaining three contrasts were all significant: Double (10) differed from Double (1), with $F=$ $119.37(p<.001)$; Single (10) differed from Single (1), with $F=5.10(p<.05)$; and the means of the Single and Double conditions were different $(F=44.98$, $\mathrm{p}<.001$ ).

The fact that a significant linear increase in alignment errors occurred in Condition Single (1), as a function of line-to-dot separation, replicates the findings of Wenderoth, Beh, and White (1978), who used only three or five alignment dots. It seems that the shift from a small to a large display screen, and the increase in figural dimensions, are not variables which affect this result.

In Condition Double (1), alignment errors continued to increase with significant linear trend. Although the slope of the error function appears slightly less than that of the Single (1) condition (Figure 5), there is a reasonable degree of continuity between the two

Table 1

Means (in Millimeters) and Standard Errors of Alignment Errors in Control Conditions, Experiment 1

\begin{tabular}{|c|c|c|c|c|c|c|c|c|c|c|c|}
\hline \multirow{2}{*}{$\begin{array}{c}\text { Control } \\
\text { Condition } \\
\end{array}$} & & \multicolumn{10}{|c|}{ Dot Position } \\
\hline & & 1 & 2 & 3 & 4 & 5 & 6 & 7 & 8 & 9 & 10 \\
\hline Single 1 & $\begin{array}{l}\text { Mean } \\
\text { SE }\end{array}$ & $\begin{array}{r}-.10 \\
.12\end{array}$ & $\begin{array}{l}.27 \\
.15\end{array}$ & $\begin{array}{l}.04 \\
.22\end{array}$ & $\begin{array}{l}.52 \\
.27\end{array}$ & $\begin{array}{l}.04 \\
.32\end{array}$ & $\begin{array}{l}.87 \\
.35\end{array}$ & $\begin{array}{l}.59 \\
.46\end{array}$ & $\begin{array}{l}.68 \\
.73\end{array}$ & $\begin{array}{l}2.06 \\
1.00\end{array}$ & $\begin{array}{r}1.69 \\
.75\end{array}$ \\
\hline Single 10 & $\begin{array}{l}\text { Mean } \\
\text { SE }\end{array}$ & $\begin{array}{l}.14 \\
.12\end{array}$ & $\begin{array}{l}.04 \\
.16\end{array}$ & $\begin{array}{l}.21 \\
.25\end{array}$ & $\begin{array}{l}.07 \\
.28\end{array}$ & $\begin{array}{l}.02 \\
.29\end{array}$ & $\begin{array}{l}.02 \\
.30\end{array}$ & $\begin{array}{l}.18 \\
.36\end{array}$ & $\begin{array}{l}.53 \\
.55\end{array}$ & $\begin{array}{r}-.04 \\
.54\end{array}$ & $\begin{array}{l}.17 \\
.59\end{array}$ \\
\hline Double 1 & $\begin{array}{l}\text { Mean } \\
\text { SE }\end{array}$ & $\begin{array}{r}.75 \\
1.05\end{array}$ & $\begin{array}{r}2.09 \\
.79\end{array}$ & $\begin{array}{r}2.51 \\
.46\end{array}$ & $\begin{array}{r}1.82 \\
.75\end{array}$ & $\begin{array}{r}2.54 \\
.89\end{array}$ & $\begin{array}{l}2.39 \\
1.02\end{array}$ & $\begin{array}{r}2.84 \\
.95\end{array}$ & $\begin{array}{l}3.14 \\
1.14\end{array}$ & $\begin{array}{l}4.16 \\
1.36\end{array}$ & $\begin{array}{l}5.02 \\
1.04\end{array}$ \\
\hline Double 10 & $\begin{array}{l}\text { Mean } \\
\text { SE }\end{array}$ & $\begin{array}{r}2.30 \\
.48 \\
\end{array}$ & $\begin{array}{r}1.93 \\
.48 \\
\end{array}$ & $\begin{array}{r}1.83 \\
.57 \\
\end{array}$ & $\begin{array}{r}1.58 \\
.52 \\
\end{array}$ & $\begin{array}{r}2.28 \\
.91 \\
\end{array}$ & $\begin{array}{l}1.51 \\
1.07 \\
\end{array}$ & $\begin{array}{r}2.72 \\
.89 \\
\end{array}$ & $\begin{array}{r}2.67 \\
.95\end{array}$ & $\begin{array}{r}3.48 \\
.97\end{array}$ & $\begin{array}{l}3.10 \\
1.01\end{array}$ \\
\hline
\end{tabular}

Table 2

Means (in Millimeters) and Standard Errors of Alignment Errors in Experimental Conditions, Experiment 1

\begin{tabular}{|c|c|c|c|c|c|c|c|c|c|c|c|}
\hline \multirow{2}{*}{$\begin{array}{c}\text { Experimental } \\
\text { Condition }\end{array}$} & & \multicolumn{10}{|c|}{ Dot Position } \\
\hline & & 1 & 2 & 3 & 4 & 5 & 6 & 7 & 8 & 9 & 10 \\
\hline Single 1 & $\begin{array}{l}\text { Mean } \\
\mathrm{SE}\end{array}$ & $\begin{array}{l}.65 \\
.16\end{array}$ & $\begin{array}{r}1.10 \\
.19\end{array}$ & $\begin{array}{r}1.65 \\
.40\end{array}$ & $\begin{array}{r}2.15 \\
.31\end{array}$ & $\begin{array}{r}2.54 \\
.62\end{array}$ & $\begin{array}{r}2.99 \\
.58\end{array}$ & $\begin{array}{r}3.26 \\
.43\end{array}$ & $\begin{array}{r}5.08 \\
.66\end{array}$ & $\begin{array}{r}5.58 \\
.78\end{array}$ & $\begin{array}{r}4.58 \\
.74\end{array}$ \\
\hline Single 10 & $\begin{array}{l}\text { Mean } \\
\text { SE }\end{array}$ & $\begin{array}{l}.69 \\
.15\end{array}$ & $\begin{array}{l}.98 \\
.20\end{array}$ & $\begin{array}{r}1.26 \\
.34\end{array}$ & $\begin{array}{r}1.75 \\
.44\end{array}$ & $\begin{array}{r}1.64 \\
.45\end{array}$ & $\begin{array}{r}1.85 \\
.66\end{array}$ & $\begin{array}{r}1.94 \\
.59\end{array}$ & $\begin{array}{r}2.03 \\
.82\end{array}$ & $\begin{array}{r}1.93 \\
.85\end{array}$ & $\begin{array}{r}2.28 \\
.83\end{array}$ \\
\hline Double 1 & $\begin{array}{l}\text { Mean } \\
\text { SE }\end{array}$ & $\begin{array}{r}5.07 \\
.52\end{array}$ & $\begin{array}{r}5.08 \\
.73\end{array}$ & $\begin{array}{r}5.75 \\
.84\end{array}$ & $\begin{array}{r}6.54 \\
.91\end{array}$ & $\begin{array}{r}7.00 \\
.95\end{array}$ & $\begin{array}{l}6.62 \\
1.02\end{array}$ & $\begin{array}{l}8.47 \\
1.01\end{array}$ & $\begin{array}{r}8.86 \\
.91\end{array}$ & $\begin{array}{l}9.03 \\
1.13\end{array}$ & $\begin{array}{r}9.00 \\
.88\end{array}$ \\
\hline Double 10 & $\begin{array}{l}\text { Mean } \\
\text { SE }\end{array}$ & $\begin{array}{r}4.37 \\
.45 \\
\end{array}$ & $\begin{array}{r}4.28 \\
.40\end{array}$ & $\begin{array}{r}4.36 \\
.39 \\
\end{array}$ & $\begin{array}{r}5.66 \\
.95 \\
\end{array}$ & $\begin{array}{r}4.86 \\
.52 \\
\end{array}$ & $\begin{array}{r}5.18 \\
.64 \\
\end{array}$ & $\begin{array}{r}5.02 \\
.83 \\
\end{array}$ & $\begin{array}{r}4.79 \\
.89\end{array}$ & $\begin{array}{l}5.53 \\
1.05 \\
\end{array}$ & $\begin{array}{l}5.64 \\
1.15 \\
\end{array}$ \\
\hline
\end{tabular}




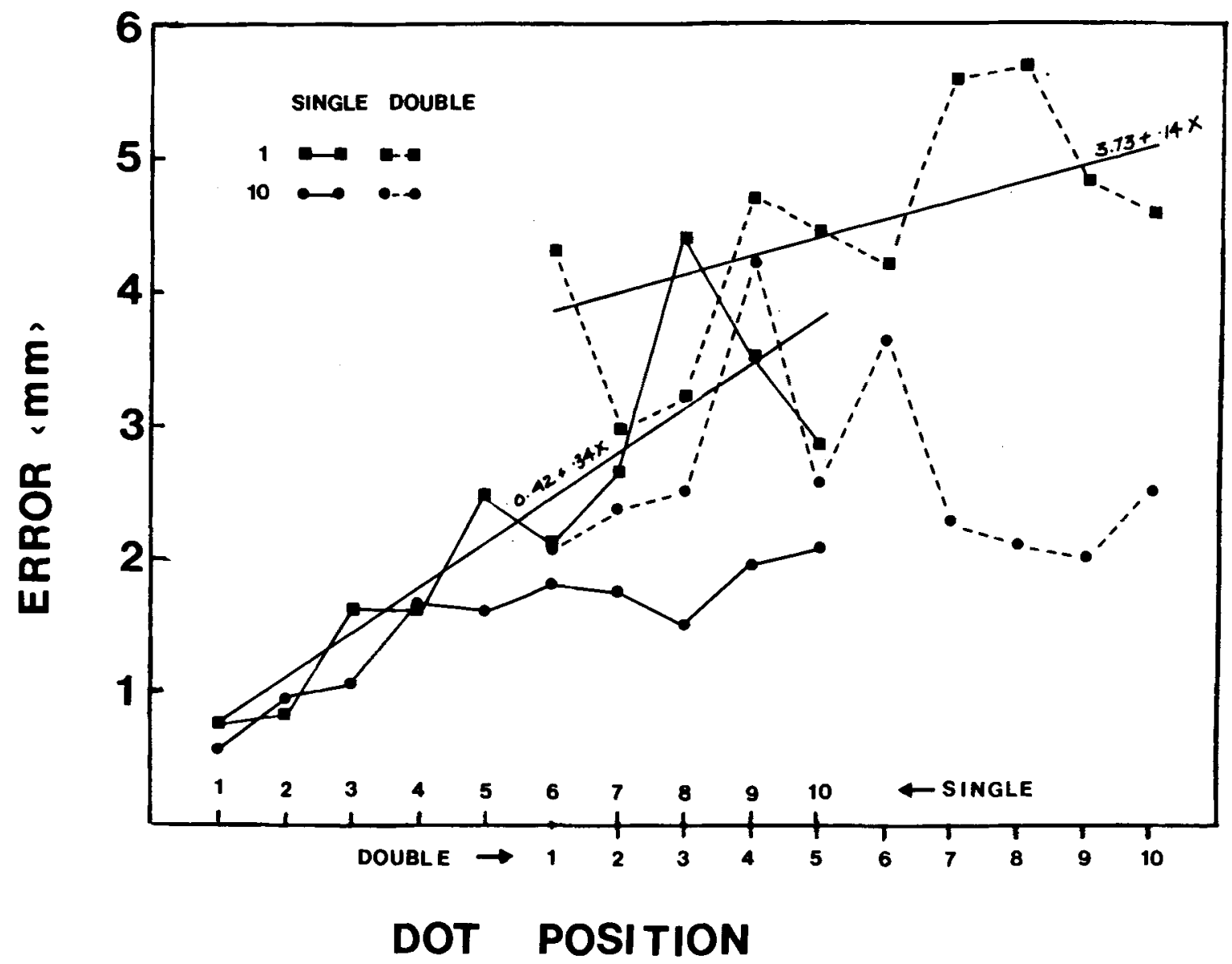

Figure 5. Alignment errors as a function of dot position, Experiment 1. Abscissa shows dot positions that were coincident (e.g., Single 6 and Double 1).

functions (but see below). Thus, the shift of the dots to the right and the introduction of the second parallel evidently had little effect on the monotonic increase in dot alignment errors, as a function of dot distance.

The results in Conditions Single (10) and Double (10) differed from the above in numerous ways. First, with all 10 dots visible in the Single (10) condition, the mean alignment error did increase with dot distance, but not significantly. Adding the second parallel in the Double (10) condition resulted in an almost flat function, for which the sole nearsignificant trend was quadratic.

Although the trend of alignment errors was monotonically increasing and linear from the Single (1) to the Double (1) treatments (as discussed above), so that the addition of the second parallel did not disrupt this linear increase, the second parallel was not without effect. The Double (1) condition caused an overall increase in mean errors: the intercept of the best fitting line was $+3.73 \mathrm{~mm}$ for Double (1) but only $+.42 \mathrm{~mm}$ for Single (1). ${ }^{4}$ Also, while a single straight line probably could be fitted quite well to the combined Single (1)-Double (1) data, the individually fitted lines differed not only in intercept, but also in slope: the best fitting lines had coefficients of $.34 \mathrm{X}$ for Single (1) and .14X for Double (1). Best fit lines were not calculated for the (10) conditions because the trends were not significant. However, the fact that errors in Double (10) exceeded those in Single (10) at all five common dot positions (Figure 5) suggests a similar linear intercept difference there; and the fact that the linear trend component approached significance in Single (10) but not Double (10) indicates a slope difference too.

\section{Discussion}

The results of Experiment 1 do suggest some resolution of the apparent paradox that single-dot alignment errors increase monotonically with line-to-dot distance, but that point $\mathrm{C}$ in Figure 1 appears more misaligned with $A B$ than the more distant point, $D$. While single-dot misalignments increased linearly with line-dot separation in both (1) conditions, this was not so in the (10) conditions; and in Double (10), inspection of the data (Figure 5) even suggests a tendency for errors to begin decreasing at the far dot 
positions, and perhaps this occurs to a lesser extent in the Double (1) data also.

It could be argued that even though 10 dots were simultaneously visible in the (10) conditions, the subjective alignment of these dots in random order is not really similar to aligning a line segment, if only because the random scatter of the surrounding dots might make the task extremely difficult, particularly when scattered dots lie between the dot to be aligned and the standard oblique line segment. It was for this reason that the subjects in Experiment 1 also completed conditions in which the dot alignment was sequential, proceeding in order from the most lefthand dot to the extreme right-hand dot. It was felt that this might more closely resemble the task of constructing a line segment to be collinear with $\mathrm{AB}$. These sequential alignments are treated below as Experiment 2, and further discussion of the results of the experiments continues there.

\section{EXPERIMENT 2}

The methods and stimuli in Experiment 2 were identical, in all respects, to those of Experiment 1, and the subjects were the same. As noted earlier, the Experiment 2 treatments were randomly interleaved with those of Experiment 1 in a single testing session. The sole difference was that Dots 1 to 10 in the Single and Double conditions were aligned sequentially.

\section{Results}

The results of Experiment 2 are treated in somewhat less detail than those of Experiment 1, mainly because they tended to differ in degree rather than in kind. Figure 6 shows the $(E-C)$ alignment errors, which were analyzed, once again, in a Subjects by Treatments design with planned contrasts identical to those used before.

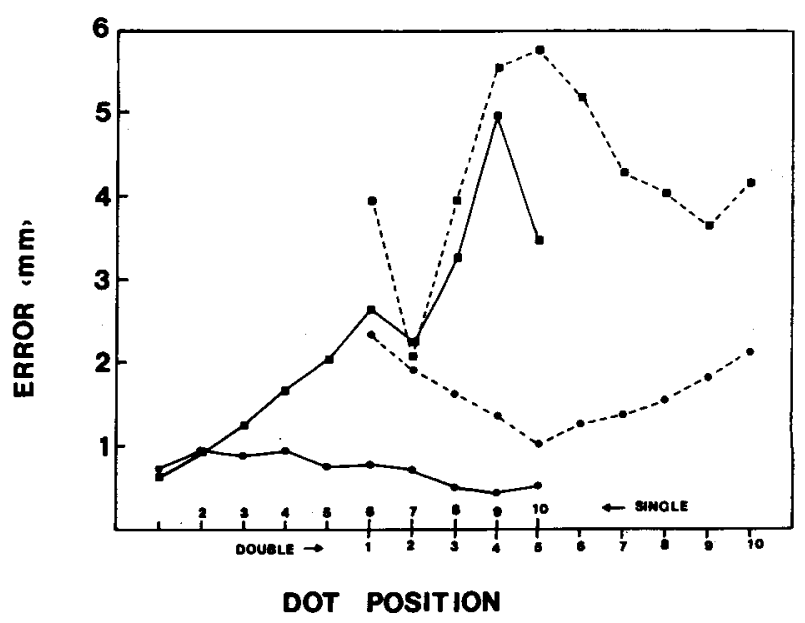

Figure 6. Alignment errors as a function of dot position, Experiment 2. Symbols as for Figure 5.
On this occasion, the only significant trends were the linear component in Single (1), with $F=16.28$ $(\mathrm{p}<.001)$, and the quadratic component in Double (1), where $F=4.20(p<.05)$. The latter result reflects the fact that errors began to decrease at the far dot distances in the Double (1) condition (Figure 6), a tendency already noted in Figure 5. No trends at all were significant in the (10) conditions, although the quadratic component was relatively large in Double (10), with $F=1.73$. As in Experiment 1, the three overall contrasts were significant: Single (1) vs. Single (10), with $F=15.37, p<.001$; Double (1) vs. Double (10), with $F=41.99, \mathrm{p}<.001$; and Single vs. Double, with $F=25.08, p<.001$.

\section{Discussion}

To the extent that a series of 10 dots, individually adjustable but simultaneously visible, represents a line segment, the results of Experiments 1 and 2 suggest that alignment errors do differ markedly with line segments and single dots. In Figure 6, for example, errors in Single (1) increased linearly with dot position; in Single (10), there was no significant trend and errors actually tended to decrease over distance.

Outside the second parallel, in the Double conditions, there were similar, although more complex, differences. Double (1) errors showed a significant quadratic trend, tending to decrease again at the further dot positions, while Double (10) errors decreased slightly, then increased again but not with any significant trend.

Rather than continuing to experiment with line-like multiple dot stimuli, it was decided to run an experiment which compared directly alignment settings made with lines and dots. The question was whether results similar to those described so far would be obtained in such an experiment. The results of Experiment 2 are discussed further in the General Discussion section.

\section{EXPERIMENT 3}

There were four conditions in Experiment 3, two control and two experimental. For reasons to be explained later, the standard (and test) transverse line segments were shortened from 44.8 to $22.4 \mathrm{~mm}$ ( $2 \mathrm{deg}$ $40 \mathrm{~min}$ ). The stimulus displays in the four conditions are represented in Figure 7.

All conditions in the experiment were similar to the (1) conditions of Experiments 1 and 2. That is, although there were the same 10 standard-to-variable stimulus distances, presented randomly, only one variable stimulus was presented at any time. The two dot conditions are shown at the left in Figure 7. In the control condition (A), subjects attempted to align a dot with the standard line segment when no vertical lines were present. In the experimental condition 


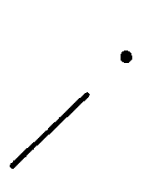

A

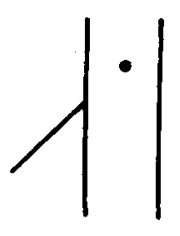

B

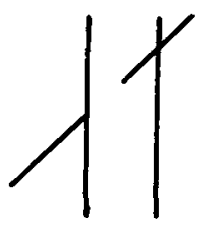

D
Figure 7. Schematic diagram of conditions used in Experiment 3 (see text).

(B), the sole difference was that the pair of vertical inducing lines was added. However, the dot positions and separations used were always those of the Single conditions in previous experiments. As a result, in the experimental condition (B in Figure 7), four of the dots fell between the parallels, the fifth dot was on the right-hand parallel, and the remaining five dots were outside it.

The two line conditions are shown to the right of Figure 7. These differed from the dot conditions in one respect only: the variable stimulus was a line segment, the left-hand tip of which always coincided with the dot positions used in the dot conditions. It was for this reason that the transverse lines were shortened in this experiment: if the variable line had been too long, it would always have overlapped the right-hand vertical line by a large proportion of its length when its near tip was between the parallels. In fact, the actual proportions of the variable line which fell to the right of the right-hand parallel in the first five conditions of separation (left to right, respectively) were: $.2, .4, .6, .8,1.00$ (standard Poggendorff display, as in Figure 1). In the remaining five conditions of separation, the whole line segment was to the right of the vertical lines and the gaps between it and the right parallel were (obliquely):

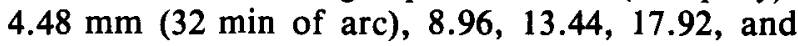
$22.40 \mathrm{~mm}$ ( $2 \mathrm{deg} 40 \mathrm{~min}$ of $\mathrm{arc})$.

\section{Method}

Apparatus. The apparatus was the same as in Experiment 1.

Procedure. The procedures were identical to those in previous experiments. The four conditions (Figure 7) were completed in a different random order by each subject.

Subjects. There were 19 subjects, 7 males and 12 females, 17 of whom were volunteers from introductory courses in psychology. The other two were a graduate student and the author.

\section{Results}

The mean alignment errors in the control and experimental conditions are shown in Figure 8 (left panel), as are the difference scores and associated standard errors (right panel).

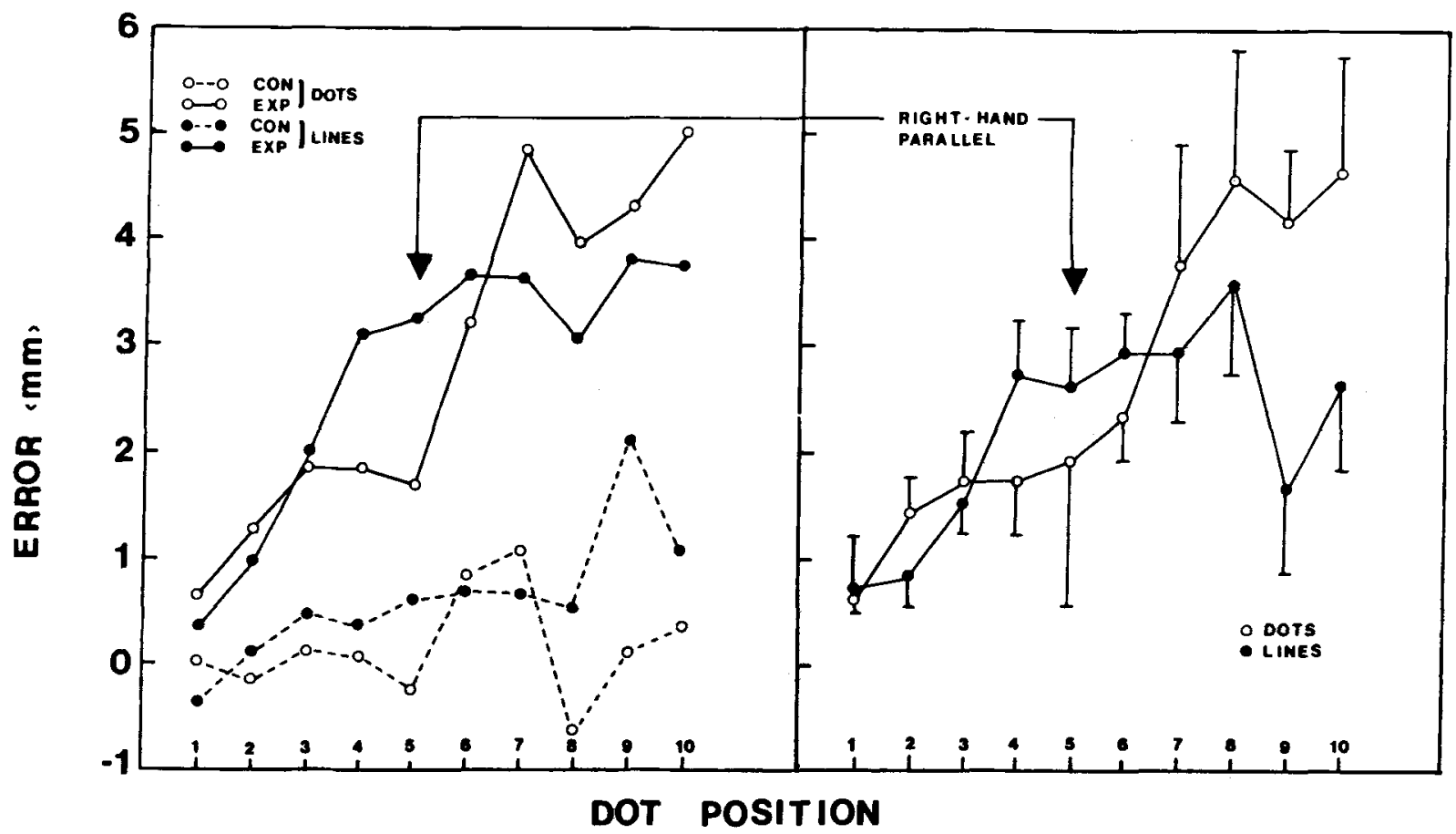

Figure 8. Left panel: Mean misalignments in Experiment 3 for control and experimental conditions. Right panel: Mean alignment errors, experimental minus control errors, Experiment 3. For each mean, plus or minus one standard error is shown. Arrows show location of right parallel (Dot 5 ) in experimental conditions. 
Once again, a Subjects by Treatments analysis with planned contrasts was employed to analyze the (E - C) data. For each treatment-dots and linesseparately, the within-subjects treatments component was partitioned into linear, quadratic, and residual trend.

Linear trend was significant in the dots treatment $[F(1,342)=40.27, p<.001]$, but the quadratic trend $[F(1,342)=.14, \mathrm{p}>.05]$ and residual trend $[F(7,342)$ $=.49, \mathrm{p}>.05]$ were not. In the lines treatment, linear trend was significant $[F(1,342)=8.27, p<.01]$ and so was quadratic trend $[F(1,432)=6.47, p<.05]$ but, again, residual trend was not significant $[F(7,342)$ $=.68, \mathrm{p}>.05]$.

The remaining contrast tested for the overall mean difference between lines and dots and was not significant $[F(1,342)=2.50, p>.05]$.

\section{Discussion}

Although the residual trend component was not significant in the dot treatment, the data appear to follow a clearly quintic trend. Thus, alignment errors were greater for the dots in Positions 2 and 3, for the lines in Positions 4, 5, and 6, and then for the dots again in Positions 7 to 10, with errors leveling off. There is some evidence that single dots are attracted perceptually to very nearby line segments (Robinson, 1972, pp. 35-37), and such effects could explain leveling off in alignment errors just before the vertical (Position 5) and the increase in slope just beyond. On the other hand, the large line alignment errors, relative to the dots, in Positions 4 and 5 could be due, in part, to tilt effects (angle expansion) which occur when two lines cross.

Apart from these minor aspects of the data, the results are consistent in many respects with those of Experiments 1 and 2. Thus, at Dot Positions 2 and 3, line errors were smaller than dot errors, as were the Single (10) compared with Single (1) errors in Experiments 1 and 2. Beyond the second parallel (Positions 6 to 10 ), dot errors continued to increase, as evidenced by the significant linear trend, but line errors began to decrease, exhibiting a significant quadratic tend. The latter differences are similar to the Double (1) and Double (10) differences in Experiment 1. Similar trends can be seen in the uncorrected experimental data (Figure 8).

Tong and Weintraub (1974) showed that greatest dot-to-line misalignments occur when the oblique line just abuts a vertical line, decreasing markedly when the oblique either cuts through the vertical or fails to reach it, leaving a gap. Here, too, it can be seen that the greatest line alignment errors to another line occurred at or near the point of abuttal.

The original problem posed in this paper was that point $D$ in Figure 1 appears less misaligned with $A B$ than does point $C$, yet dot alignment errors (as in the
Single (1) condition of Experiment 1, increase with line-to-dot separation. Can the data presented here resolve this apparent paradox?

If the observer is asked to align a dot with the apparent extension of a line segment, and if the abutting segment appears bowed, as in Figure 9, then dot alignment errors should increase with line-to-dot separation as Wenderoth, Beh, and White (1978) found. Figure 9A shows that a perceptually bowed transverse line segment could be conceived as having two main directional components, a relatively veridical one near its free end, where dot alignment errors have been shown to be minimal (Wenderoth et al., 1978), and a distorted directional component near its abutting end (arrows labeled T and D, respectively, in Figure 9A). This bidirectionality should not make alignment judgments in a Single condition difficult, however, because the observer merely is asked to project visually the extension of the transverse segment from its abutting end. The task is not to align the variable with the whole line. If, on the other hand, both parallel vertical lines and both transversals are present (Figure 9B), then a conflict situation could arise. First, if the observer adjusted the transversals so that their abutting ends appeared to point to each other, then the longer, relatively undistorted parts of the lines would be clearly misaligned. Yet, if the relatively undistorted free ends were aligned perceptually, the abutting segments would appear vertically misaligned.

These considerations could explain the original observation made earlier: When asked to align point $C$ in Figure 1 with $\mathrm{AB}$, most weight (attention?) is given to the markedly distorted directional component; but in aligning point $D$, the observer primarily uses the relatively undistorted directional components given by the free ends of both of the lines. Consequently, the fact that dot alignment errors increase with linedot separation does not necessarily conflict with the smaller errors made in aligning the more distal portion of a line segment. Thus, in these terms, dotalignment errors increase with distance because they index the direction in which the closer tip of the line segment is pointing, whereas line alignment errors

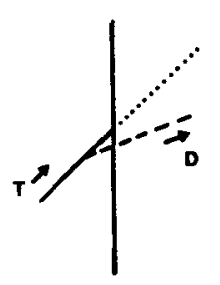

A

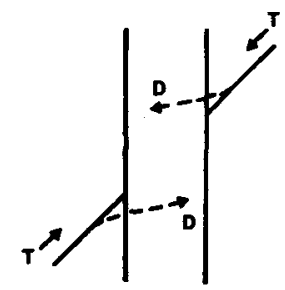

B
Figure 9. Directional components in Poggendorff figures on the hypothesis that abutting lines bow (see text). 
represent some kind of compromise judgment which may be based to a greater or lesser extent on the closest tips of the two lines, on the average direction of both of the lines, on the direction of the more distal portions, or even some other combination of factors. The fact that it is difficult to demonstrate that a line appears bowed (Wenderoth et al., 1979) does not mean that the effect does not occur just at the very tip of the line, and there are some displays in which bowing is evident (Schilder \& Wechsler, 1936). Long lines apparently accentuate the effect (Schilder \& Wechsler, 1936), and, indeed, some of the subjects in Experiment 1 reported it after I had observed it and questioned them about it. ${ }^{5}$

One way to test the above ideas might be to instruct observers to use various strategies. If, for example, subjects are asked to align only the nearer tip of the variable line segment, the above considerations might predict identical, or similar results for dots and lines as a function of standard-variable separation. This prediction was tested in Experiment 4.

\section{EXPERIMENT 4}

A question raised by Experiment 3 is whether the different results obtained with dot-line alignment and line-line alignment is largely one of perceptual processing of lines and dots, so that the near tip of a variable line is perceived to be in a different place from a dot with identical physical coordinates, or whether observers merely respond differently by using different strategies, or invoking compromise judgments of some kind, in attempting to align two lines.

A way to find out might be to instruct observers, when setting a line segment, either to attempt to align the whole line segment or to ignore the bulk of the line and merely to align the near tip. If the near tip is seen perceptually to lie in the same place as a dot with the same coordinates, then "near-tip" instructions might be expected to produce a linear increase in errors, as occurs with dots. However, if the presence of a whole line segment distorts the perceived position of the near tip, then line alignment errors might continue to show a decline beyond the second parallel (as in Experiment 3) despite the instruction, or at the very least might continue to differ significantly from the results obtained with dots. Experiment 4 tested these predictions with three treatment (and corresponding control) conditions: line-dot alignment (DOTS), line-line alignment with whole-of-line instructions (LINES), and line-line alignment with near-tip alignment instructions (LINES-N). Apart from the different instructions and the use of a different display screen (see below), the experiment was identical to Experiment 3.

\section{Method}

Apparatus. For this experiment, the PDP-8/E computer was interfaced with a Tektronix 604 display monitor (P4 phosphor) with a smaller, but flat, screen. Observers were seated $57 \mathrm{~cm}$ from the display so that $1 \mathrm{~cm}$ on the screen subtended $1 \mathrm{deg}$ of visual angle. The chinrest and microswitch arrangement described earlier was used once again, although now the dot or line segment moved along the vertical track at a velocity of $1.25 \mathrm{~mm}(7.5 \mathrm{~min}$ of arc)/ sec. Dot or line starting positions were random, with the restriction that they be within $\pm 12.5 \mathrm{~mm}$ from true alignment. The presentation order of the 10 dot positions within a treatment was random. Each subject completed the DOTS treatment first, but then the order of the other two treatments (LINES or LINES-N) was random between subjects.

Visual display. The display screen was set so that one dot measured $.1 \mathrm{~mm}$ ( $36 \mathrm{sec}$ of arc). The change in viewing distance and screen size resulted in all stimulus dimensions (in millimeters) being reduced to .625 of their values in Experiment 3. Thus, for example, the oblique line segments were $14 \mathrm{~mm}$ (1 deg $24.5 \mathrm{~min}$ of arc) long. The standard oblique line segment abutted the left vertical (when present) $45 \mathrm{~mm}$ from its lower end. Display luminance, and hence contrast, was similar to that in previous experiments.

Procedure. Test sessions lasted $1 \mathrm{~h}$, and each subject completed six conditions, both control (verticals absent) and experimental (verticals present) for treatments DOTS, LINES, and LINES-N. The control measures always preceded their relevant experimental conditions.

The subjects were instructed as follows:

"In this experiment, your task is to try to line up one stimulus with another, either a dot with a line or one line with another (subject shown drawing). As this shows, any dot can move up or down. Try to set the dot so that it looks to you as if it lies on the apparent extension of $\mathbf{A B}$ (dotted line on illustration).

"Here (next illustration) line CD can move up or down. Try to set CD so that it looks to you as if it lies on the apparent extension of $A B$ (dotted).

"We'll explain how you can set the dots or lines in a moment. First, I want to stress some important things about the experiment. When you are trying to align two lines we're just not sure whether it makes any difference how you do it. First you could do it like this (illustration): As the line moves up and down, just concentrate on the nearest tip of the line (arrowed in illustration) and ignore the rest of the line: pretend there's only a dot, no line. That's one way. We'll call it: NEARTIP METHOD.

"Another way would be to take the whole line into account, to find the position of the movable line which most makes it look as if there's one long continuous line with a gap. Call this the WHOLE LINE METHOD. Do you understand this distinction?

"The reason for making this distinction is that although the two lines in the experiment will always be parallel they mightn't always LOOK parallel. And if they didn't you wouldn't know how to do the task-NEARTIP or WHOLE LINE (illustrated). So: In the experiment, sometimes we'll ask you to use one method, sometimes the other. Please, try to use exactly the method we tell you and not the other, because we want to find out if it makes any difference.

"Also, please do the task normally without screwing up your eyes; don't tilt your head and don't try to 'cheat' in any way. And-please-do the task as accurately as you can-take your time if necessary: we'll tell you if you're being too slow or fast. The buttons will let you move the dot or line up and down as often as you wish. So please try hard, even if you get bored or tired. OK? And set everything so it looks OK, not how you think we want you to, or how you might think it should look.

"If you need a rest, say so, but you'll have short rests between conditions anyhow.

"Oh-and sometimes if other lines appear (vertical parallels illustrated), don't worry-ignore them-just do the same alignment task. OK? Any questions before we show you how the switches work?"

Subjects. Eighteen students from an advanced undergraduate course in perception acted as subjects, nine males and nine 
Table 3

Mean Alignment Errors (in Millimeters) and Standard Errors in Control Conditions, Experiment 4

\begin{tabular}{|c|c|c|c|c|c|c|c|c|c|c|c|}
\hline \multirow{2}{*}{$\begin{array}{c}\text { Control } \\
\text { Condition }\end{array}$} & & \multicolumn{10}{|c|}{ Dot Position } \\
\hline & & 1 & 2 & 3 & 4 & 5 & 6 & 7 & 8 & 9 & 10 \\
\hline Dots & $\begin{array}{l}\text { Mean } \\
\text { SE }\end{array}$ & $\begin{array}{l}.190 \\
.007\end{array}$ & $\begin{array}{l}.390 \\
.012\end{array}$ & $\begin{array}{l}.580 \\
.013\end{array}$ & $\begin{array}{l}.780 \\
.019\end{array}$ & $\begin{array}{l}.960 \\
.023\end{array}$ & $\begin{array}{r}1.150 \\
.022\end{array}$ & $\begin{array}{r}1.370 \\
.032\end{array}$ & $\begin{array}{r}1.540 \\
.031\end{array}$ & $\begin{array}{r}1.730 \\
.037\end{array}$ & $\begin{array}{r}1.940 \\
.033\end{array}$ \\
\hline Lines(N) & $\begin{array}{l}\text { Mean } \\
\text { SE }\end{array}$ & $\begin{array}{l}.210 \\
.008\end{array}$ & $\begin{array}{l}.400 \\
.019\end{array}$ & $\begin{array}{l}.580 \\
.021\end{array}$ & $\begin{array}{l}.780 \\
.034\end{array}$ & $\begin{array}{l}.980 \\
.027\end{array}$ & $\begin{array}{r}1.190 \\
.025\end{array}$ & $\begin{array}{r}1.350 \\
.046\end{array}$ & $\begin{array}{r}1.540 \\
.048\end{array}$ & $\begin{array}{r}1.760 \\
.046\end{array}$ & $\begin{array}{r}1.980 \\
.044\end{array}$ \\
\hline Lines & $\begin{array}{l}\text { Mean } \\
\text { SE }\end{array}$ & $\begin{array}{l}.200 \\
.009\end{array}$ & $\begin{array}{l}.390 \\
.009\end{array}$ & $\begin{array}{l}.580 \\
.013\end{array}$ & $\begin{array}{l}.740 \\
.021\end{array}$ & $\begin{array}{r}1.000 \\
.022\end{array}$ & $\begin{array}{r}1.170 \\
.026\end{array}$ & $\begin{array}{r}1.350 \\
.020\end{array}$ & $\begin{array}{r}1.530 \\
.049\end{array}$ & $\begin{array}{r}1.740 \\
.040\end{array}$ & $\begin{array}{r}1.870 \\
.043\end{array}$ \\
\hline Mean* & & .200 & .390 & .580 & .770 & .980 & 1.170 & 1.360 & 1.540 & 1.740 & 1.930 \\
\hline
\end{tabular}

*Mean over all conditions.

females, aged between 21 and 38 years. The experiment was run to collect data for a class exercise, but the data were collected before the course began so that subjects were totally ignorant of the experimental aims. All subjects, however, were relatively experienced experimental observers.

\section{Results}

The results of the control conditions (no verticals present) are considered first, followed by the difference (experimental minus control) scores.

Control conditions. Some of the subjects, when asked to comment after the experiment, reported that in the LINES (and LINES-N) control conditions, the two oblique line segments sometimes did not appear parallel, but rather appeared to converge upwards, towards the center of the display. This was so even though fixation generally was between the lines and not above or below them (see Wenderoth, White, \& Beh, 1978). I had previously observed this phenomenon, although less advanced undergraduate students than those used here have rarely reported it in this laboratory, even after direct questioning. However, Weintraub noted that his subjects often complained of the difficulty of aligning apparently nonparallel lines, even when the vertical inducing lines were also present (see Tong \& Weintraub, 1974; Weintraub \& Krantz, 1971), although my own, informal observations suggest that the effect is more obvious in the absence of the vertical inducing lines.

The relevance of this observation to the present study is that, as a consequence of the effect, at least some of the subjects admitted to using the LINES-N strategy, despite the contrary instruction in the LINES control treatment, simply because a wholeof-line alignment seemed impossible. The data bear out these observations: The means and standard errors of the three control-condition alignment errors are shown in Table 3; and it can be seen that the differences between the three conditions are minimal, to the extent that it was not possible to plot the three functions on the one graph. Hence, the means were averaged over the three conditions and the average function is shown in Figure 10. Clearly, the increase in errors as a function of dot or line separation was almost perfectly linear with almost zero intercept: the solid line in Figure 2 is not a fitted function, but merely joins the first dot (1) to the last (10). These results confirm previous observations that alignment errors increase linearly with separation, whether the visual display is relatively large (Experiment 3) or small, as here (Wenderoth, Beh, \& White, 1978; Wenderoth, White, \& Beh, 1978).

Experimental (E) minus control $(C)$ conditions. Meán errors for the three $(E-C)$ conditions are shown in Figure 11 for DOTS (open circles), LINES (filled squares), and LINES-N (filled circles). The solid lines are functions derived from the analysis of variance, using orthogonal polynomials (see below).

The data were analyzed using a single-factor (Subjects by Treatments) design, and the within-subjects treatments component was partitioned into planned contrasts. For each condition (DOTS, LINES, LINES-N), the contrasts tested were those for linear, quadratic, and residual (higher order) trend, with one exception. In Experiment 3, it was found that dot alignment errors tended to decrease slightly just before reaching the second parallel (Positions 3 and 4) and to increase sharply, before decreasing again, just

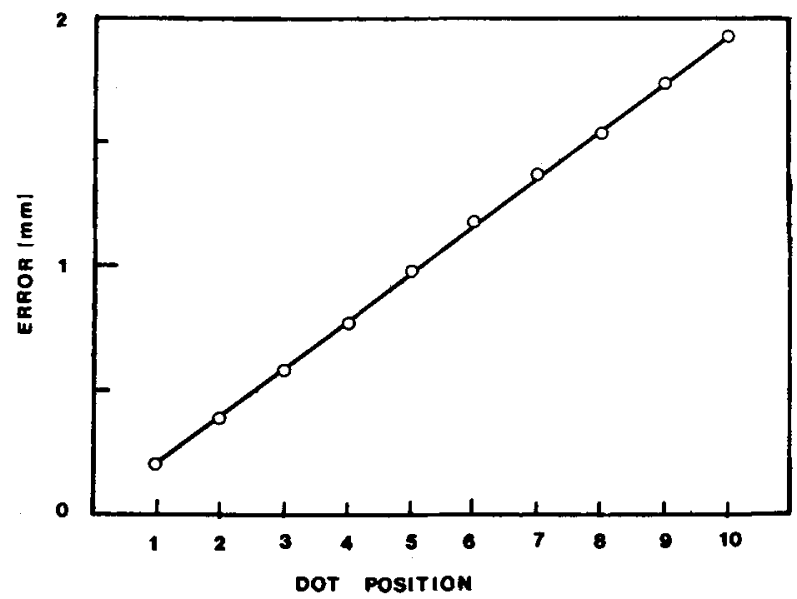

Figure 10. Alignment errors as a function of dot position in the control condition, Experiment 4, averaged over groups. 


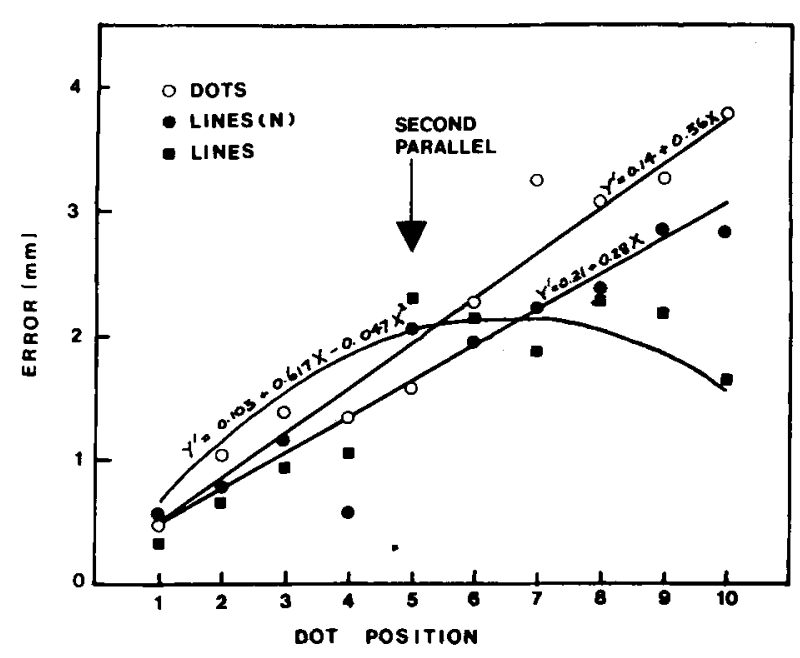

Figure 11. Mean alignment errors, experimental minus control, Experiment 4, for DOTS (open circles), LINES-N (filled circles), and LINES (filled squares) groups. Fitted functions explained in text.

beyond it (Positions 6 and 7). Hence, although only linear trend was significant in Experiment 3, the data had the clear appearance of quintic trend as well, and it was suggested that this might occur, with dots, because dots are attracted perceptually towards nearby lines. For this reason, in the DOTS condition only, I predicted both significant linear and quintic trend.

The results were as follows. For DOTS, the linear trend component was significant, with $F(1,493)=$ 85.82 ( $p<.0005$ ). Although the means again did show clear evidence of quintic trend (see above and Figure 3), it was not significant $[F(1,493)=2.41$, $\mathrm{p}>.05]$ and no other trends were significant.

For LINES-N, the linear component was significant, with $\mathrm{F}(1,493)=49.41(\mathrm{p}<.0005)$, but the quadratic $(F=.02)$ and residual trends $[F(7,493)=.98]$ were not.

In the case of the LINES condition, as predicted, and as found using lines but without special instructions previously, both the linear $[F(1,493)=23.94$, $\mathrm{p}<.0005]$ and quadratic $[\mathrm{F}(1,493)=9.05, \mathrm{p}<.005]$ components were significant, with a nonsignificant residual trend $[F(7,493)=.79]$.

For all three conditions, the best fit functions were calculated from the polynomial analysis as before, and are given in Figure 11. The curvilinear function for the LINES condition was not a good fit at the closer dot positions $(2,3,4)$, and inspection suggests that a better description of the data would be provided by two straight lines, one with positive slope for Positions 1 to 4 (or 5) and one with negative slope for Positions 5 (or 6) to 10.

Although the results for DOTS and LINES-N were very similar, the slope of the LINES-N function (.28) was less than that of the DOTS function (.36), and the overall difference between DOTS and LINES-N was significant $[F(1,493)=6.47, p<.025]$. The mean DOTS error was $2.15 \mathrm{~mm}$; that for LINES-N was $1.74 \mathrm{~mm}$. The LINES overall mean $(1.54 \mathrm{~mm})$ also differed from the average of these other two conditions $(1.95 \mathrm{~mm})$, with $F(1,493)=9.36(\mathrm{p}<$ $.005)$.

\section{Discussion}

This experiment has shown that instructions to attend to certain parts of the variable line segment can markedly affect alignment error functions obtained with a Poggendorff-type display. When observers were instructed to align only the nearer tip of the line segment with the standard line, a linear increase in errors occurred as a function of standardto-variable distance, similar to the function obtained with variable dots (Figure 11). On the other hand, instructions to align the whole variable line segment resulted in a curvilinear (or double linear, see above) function, with errors beginning to decrease as the variable line moved beyond the second parallel. This latter result was similar to that obtained in Experiment 3 , in which no special instructions were given on how to do the task.

A question that arises is whether, in the latter experiment, subjects differed in the strategies they chose to adopt. That is, without specific instructions, do some subjects adopt a whole-of-line strategem, while others choose merely to align the near tip of the line?

Figure 12 presents the data of Experiment 3, but shows individual subject data. Thus, each point represents one setting by one subject, with 19 subjects in all. Inspection of Figure 4 suggests that although variability is high at the further dot positions and a small number of subjects made very large errors, similar to dot alignment errors, nevertheless, at those further positions, most subjects' data follow a curvilinear function, with errors decreasing beyond the second parallel.

On the other hand, there are aspects of the data in Figure 11 which strongly suggest that instructions cannot completely eradicate differences between dot and line alignments. First, the DOTS and LINES-N results were significantly different. Second, at the position of the second parallel (Position 5), the mean alignment errors for LINES $(+2.30 \mathrm{~mm})$ and LINES-N $(+2.09 \mathrm{~mm})$ exceeded the mean for DOTS $(+1.57 \mathrm{~mm})$. This occurred despite the fact that the LINES and LINES-N means at the flanking positions (4 and 6) were smaller than the DOTS means (Position 4: 1.05, .57 , and $1.33 \mathrm{~mm}$, respectively; Position 6: 2.13 , 1.97 , and $2.27 \mathrm{~mm}$, respectively). This observation was not tested statistically in the planned contrasts analysis, but it can be noted that at all other positions (except 1) dot errors exceeded the others and, furthermore, the reversal at Position 5 is entirely consistent with the speculations outlined earlier in 


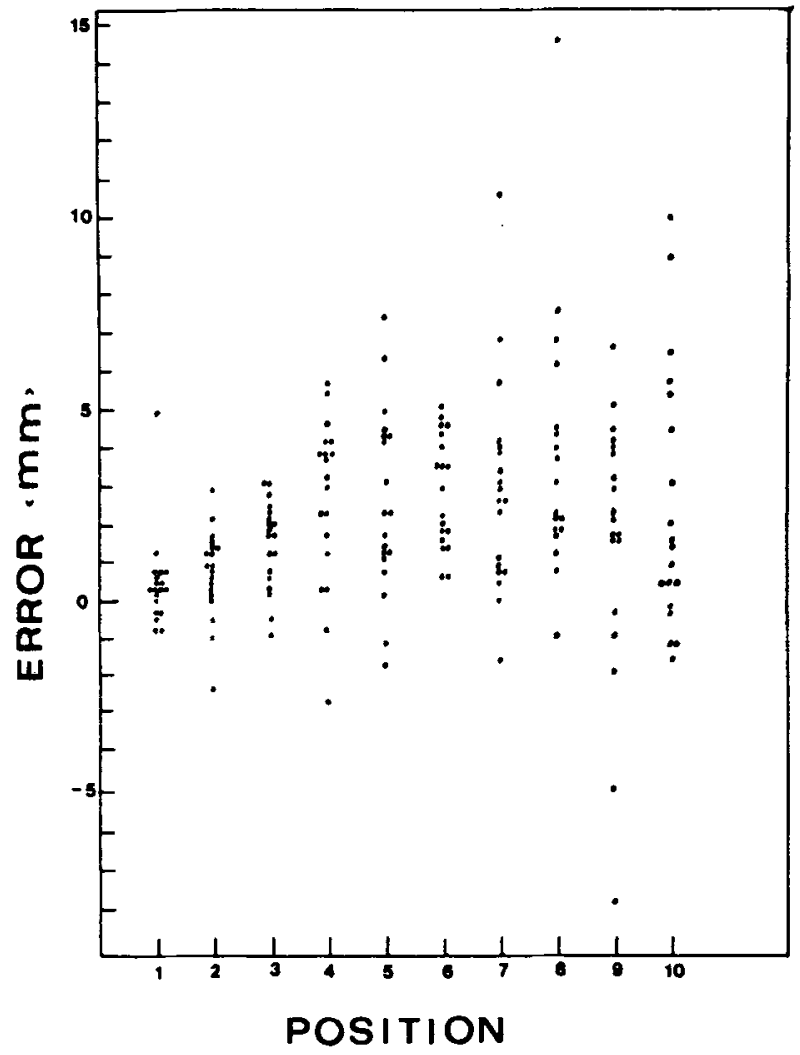

Figure 10. Individual subject means for function in Figure 8, right panel, lines condition.

relation to Figure 9. To elaborate: Experiment 4 has shown that line-line alignments can be rendered dot-like merely by instructing observers to use only the near tip in making judgments. This suggests that a large part of the difference between line and dot alignments beyond the second parallel is due to response (strategy) differences. However, if one of the factors contributing to Poggendorff errors is an actual line-bowing effect (Figure 9), then, at Position 5, such bowing will occur regardless of the instructions and large errors would be predicted to occur there in both the LINES and LINES-N treatments. This precisely is what Figure 11 demonstrates.

\section{GENERAL DISCUSSION}

Let us first summarize the main results of the four experiments described here and then ask what these data suggest regarding the determinants of Poggendorfftype illusions.

A quite general finding, in all of the experiments, is that errors of alignment increase systematically (generally linearly) as a function of line-to-dot separation, when the variable stimulus in a Poggendorfftype display is a single dot. However, if the variable stimulus is a series of dots, a line-like stimulus, or an actual line segment, alignment errors either fail to increase consistently or even begin to decrease as the closest dot or the tip of the variable line passes beyond the second parallel. Even when the nearest dot or the line's near tip is between the two parallels, errors do not increase significantly with distance for line-like stimuli (Experiments 1-3), except under special instruction conditions (Experiment 4).

Two proposals, taken together, seem able to account for the large part of these data. First, Krantz and Weintraub (1973) showed that perceptual processing of Poggendorff-type displays was asymmetrical. This conclusion followed from experiments which showed that a single display might or might not result in significant alignment errors, depending upon which segment was the variable stimulus. For example, one of their figures comprised a vertical line segment flanked by a lower left dot and an upper right dot. In processing left to right (upper dot variable), the perceptual track makes a virtual obtuse angle with the lower tip of the vertical line; processing right to left (lower dot variable) results in a virtual acute angle (Krantz \& Weintraub, 1973, pp. 516-517). Only in the former case did significant illusions occur. The relevance of this observation here is that when the variable stimulus is a single dot, processing is forced to be asymmetrical, in the sense that the dot must be set to index the direction in which the fixed line is pointing: it is meaningless to speak of judging the fixed line's position in relation to the dot's direction, because a dot has no direction.

When, on the other hand, the variable stimulus is composed of a line or a series of dots, processing can proceed in both directions. The observer can make judgments of alignment either by asking whether the upper-right variable line (or dots) continues the track of the lower standard line; or whether the lower line continues the track of the upper variable line (or dots); or, indeed, both (i.e., judgment of parallelism).

Now, Experiment 3 showed (Figure 8) that errors in setting the upper variable line segment began to decrease as the near tip of the line passed beyond the second parallel; this decrease in errors did not occur with single dots. This result is explicable in terms of asymmetrical processing. When the variable line is wholly beyond the parallel, it abuts nothing and presumably is therefore undistorted. Because it is a directed line segment, processing can proceed from variable to standard as well as the other way.

If the standard line is distorted due to its abutting a parallel, as in Figure 9, but mainly at its near tip (second proposal), then processing from right to left would most likely result in the observer's ignoring this small distortion at the tip when the variable stimulus is a line (or line-like). Otherwise, consider what would happen if processing began from left to right and the near tip of the variable line was placed so that it lay on the apparent extension of the stan- 
dard. If the observer did this, and then tracked back the other way, the bulk of the standard line would clearly now lie above the variable: only its tip would be aligned. In brief, it is proposed here that when the variable stimulus in these experiments was line-like or a line, this provided the opportunity to process in both directions and, in cases where the variable line made no intersection, extra cues to veridical judgment were available when processing right to left because the variable stimulus was relatively undistorted. This also applies to the multidot stimuli of Experiments 1 and 2 [Single (10) and Double (10)], because none of the dots actually abutted the parallels; hence, the 10 dots could be positioned so that their direction pointed to the bulk of the standard line, a strategy not available in the Single (1) and Double (1) conditions.

There is some other factor implicated in alignment errors by the data of Experiments 1 and 2. It will be recalled that, even though errors did not change significantly as a function of standard-variable separation either within the parallels or beyond them in the Single and Double (10) conditions, there appeared to be an overall increment in errors in the latter relative to the former. In other words, the introduction of the second parallel boosts errors when the variable is a line (or line-like). I would not like to speculate on the nature of this factor here, but there are various candidates in the literature, including notions like parallel line attraction, shrinkage of acute angle arms, depth processing, and so on. The major point to be made here is that if the Poggendorff effect has multiple determinants and if two of these are those discussed above (line bowing at intersect and the role of asymmetrical processing), then much of the data reported here is comprehensible in those terms.

The results of Experiment 4 can also be understood in these terms. When observers are asked to align the whole variable line segment with the standard, not just the near tip of the variable, this is tantamount to asking for symmetrical processing, to asking the observer to make each of the line segments point to the other. Hence, errors fail to increase linearly as the variable line leaves the second parallel. However, when near-tip alignment is instructed, this is tantamount to asking the observer to ignore the directionality of the variable line and to process only in the direction from standard to variable, attending only to the tip of the variable line. Thus, a result similar to that with a variable single dot is obtained.

Of interest too, perhaps, is the fact that this analysis may also have relevance for data obtained when the orientation of the variable line segment is varied. A number of investigators have found that errors are smallest when, in a standard Poggendorff display, the standard and variable line segments are parallel (Pressey, 1976; Weintraub \& Krantz, 1971). This might be so because only in that case is bidirectional processing possible. When the variable line is, say, orthogonal to the standard, the task can be done only by aligning the near tip of the variable and by processing from standard to variable. It has been reported that roughly equivalent errors occur when the variable line is parallel to or orthogonal to the standard (Day, 1974). It could be suggested that although the relatively minor effect of line bowing would tend to decrease errors in the orthogonal case, this would be counteracted by the need to process asymmetrically, with the tendency to increase the illusion, since the cue of parallelism is no longer available.

\section{REFERENCES}

Chiang, C. A new theory to explain geometrical illusions produced by crossing lines. Perception \& Psychophysics, 1968, 4, 174-176.

DAy, R. H. The Poggendorff illusion: Apparent displacement of the oblique lines. Australian Journal of Psychology, 1974, 26, 49-60.

Day, R. H., \& Dickinson, R. G. The Poggendorff illusion: Apparent misalignment which is not attributable to apparent orientation of the transversals. Quarterly Journal of Experimental Psychology, 1975, 27, 551-557.

Hays, W. L. Statistics for psychologists. New York: Holt, Rinehart \& Winston, 1963.

Krantz, D. H., \& Weintraub, D. J. Factors affecting perceived orientation of the Poggendorff transversal. Perception \& Psychophysics, 1973, 14, 511-517.

Pressey, A. W. The effect of rotating the distal arm in the Poggendorff configuration: A replication. Bulletin of the Psychonomic Society, 1976, 7, 554-556.

Restle, F. Illusions of a bent line. Perception \& Psychophysics, 1969, 5, 273-274.

RoBinson, J. O. The psychology of visual illusion. London: Hutchinson, 1972.

Schilder, P., \& Wechsler, D. The illusion of the oblique intercept. Journal of Experimental Psychology, 1936, 19, 747-757.

Tong, L., \& Weintraub, D. Contour displacements and tracking errors: Probing 'twixt Poggendorff parallels. Perception \& Psychophysics, 1974, 15, 258-268.

WALKER, E. H. A mathematical theory of optical illusions and figural aftereffects. Perception \& Psychophysics, 1973, 13, 467-486.

Weintraub, D. J., \& Krantz, D. H. The Poggendorff illusion: Amputations, rotations and other perturbations. Perception \& Psychophysics, 1971, 10, 257-264.

WENDEROTH, P. A theoretical puzzle in a visual alignment task. Australian Journal of Psychology, 1980, in press.

Wenderoth, P., Beh, H., \& White, D. Perceptual distortion of an oblique line in the presence of an abutting vertical line. Vision Research, 1978, 18, 923-930.

Wenderoth, P., Parkinson, A., \&. White, D. A comparison of visual tilt illusions measured by the techniques of vertical setting, parallel matching and dot alignment. Perception, 1979, 8, 47-57.

Wenderoth, P., White, D., \& Beh, H. The effects of peripheral and central fixation on a Poggendorff-like vernier alignment task. Perception \& Psychophysics, 1978, 24, 377-386.

WINER, B. J. Statistical principles in experimental design. New York: McGraw-Hill, 1962. 


\section{NOTES}

1. In previous research, I have preferred to use an $\alpha-16 \mathrm{mini}-$ computer interfaced with a flat screen Tektronix 604 display. Unfortunately, this system has been inoperable for some months. However, at least some control over screen curvature is built in to the present experiments because control conditions (no vertical inducing lines) were also run. In addition, one of the treatments (Single 1) virtually replicates previous findings with the other system.

2. To avoid confusion, visual angles at the eye (i.e., sizes) are given as "deg," "min," etc.; orientations or angles made between lines are given as " "," etc.

3. $\mathrm{L}_{\max }$ and $\mathrm{L}_{\min }$ are the maximum and minimum luminances on the screen. Hence, because the luminance of the screen areas in which lines were absent was below the lower limit of the photometer, the line luminance was sufficient to give contrast near unity.
4. Best fit lines were calculated from the polynomial trend analysis data (Hays, 1963, pp. 558ff), and intercepts and slopes were then calculated using the fact that the linear contrast coefficients (cj) are equal to $2\left(x-M_{x}\right)$.

5. It has been noted elsewhere that such bowing is detectable in some displays but not others and that it is difficult to measure (Wenderoth et al., 1979). The effect may be a function of figure size (spatial frequency). Thus, Day and Dickinson (1975) state that the lines in their Figure 1 do not appear bent; but they do. Perhaps Day and Dickinson failed to see bowing in their enlarged original figure. These issues will not be addressed further here. For present purposes, it is assumed that a line may curve or bow slightly, whether or not this is easily detectable.

(Received for publication September 17, 1979; revision accepted January 27,1980 .) 